\title{
Lipids of deepwater endemic sponge Baikalospongia intermedia profundalis
}

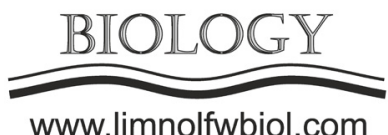

\author{
Bazarsadueva S.V.*, Radnaeva L.D. \\ Baikal Institute of Nature Management, Siberian Branch of the Russian Academy of Sciences, Sakh'yanovoy str., 6, Ulan-Ude, 670047, \\ Russia
}

\begin{abstract}
In this report, we study lipid components (fatty acids with various degrees of unsaturation, aldehydes and sterols) of deep-water sponges Baikalospongia intermedia profundalis sampled using deepwater manned submersibles "Mir" at depths of 150-1520 meters for the first time. It was found that unsaturated fatty acids predominate in the fatty acid composition of the sponges: very long chain demospongic acid 26:3, as well as monounsaturated 24:1 and isomers of acids 16:1 and 18:1. Among the saturated fatty acids myristic $14: 0$, palmitic 160 and stearic $18: 0$ acids are predominate. In addition significant amounts of acids of microbial origin (iso-palmitic i16:0, isostearic i18:0, oxy-stearic 10h18) were detected.
\end{abstract}

Keywords: Baikalospongia intermedia profundalis, Baikal, lipids, deepwater freshwater sponge

Among aquatic animals, sponges possess the highest variety of sterols and fatty acids (FA) with unusual, sometimes unique structures. Some sponge lipids are characterized as biologically active (Ichiba et al., 1995; Carballeira et al., 2002). Sponges are of highest interest for the indicative assessment of natural environment since they represent a stable habitat and are associated with a wide range of microorganisms and contain a high number of secondary metabolites playing an important role in the development of adaptive reactions during ecological changes. There are studies of lipid components of some Baikal sponges living at shallow depths to $50 \mathrm{~m}$ (Dembitsky et al., 2003), but lipids of deep-water sponges of Lake Baikal have not been studied. We published the first data on lipids of deepwater endemic sponges Baikalospongia intermedia recently (Radnaeva et al., 2020). In the present study, we defined the composition of lipid components, including fatty acids, aldehydes and sterols, of the deepwater sponge Baikalospongia intermedia profundalis at the first time.

Deepwater sponges $B$. intermedia profundalis were collected in August of 2008-2010 at depths of from 150 to $1520 \mathrm{~m}$ with using deep manned submersibles "MIR". Sponges were sampled from such areas of Lake Baikal as Tolsty cape, Bolshie Koty, Posolsk banka, Izhimey cape, Barguzin bay and the area of the mouth of the Turka River. Total lipids varied between 10.0 and $12.8 \%$ dry wt. 94 compounds were found and identified in the composition of sponge lipids. The dominating one among them is a palmitic $16: 0$, stearic $18: 0$ and myristic
14:0 acids, which are also dominating in the majority of marine shallow-water sponges (Zhukova, 2009). In sponges $B$. intermedia inhabiting in southern part of Lake Baikal at the depth of 8-10 meters the main saturated FA is palmitic acid 16:0 (11.1 rel. \%) (Dembitsky et al., 2003). Significant amounts of acids of microbial origin (iso-palmitic i16:0, isostearic i18:0, oxy-stearic 10h18) were detected. The content of monounsaturated fatty acids (MUFA) in the studied sponges varies from 11.9 to $14.8 \%$ from the sum of FAs. The content of polyunsaturated fatty acids (PUFAs) in the sponges $B$. intermedia profundalis is varied: sponges from Tolsty cape contain the least amount (6.8 rel.\%), sponges from Bolshie Koty and Barguzin consist from 13.7 to $15.1 \%$ and sponges from Posolsk Banka, Turka and Izhimey consist from 19.0 to $25.5 \%$ of total FA. Isomers of $16: 1$ and 18:1 acids and 24:1 acid are dominant among the MUFA. The demospongic very long-chain acid 26:3 brings the main contribution in the sum of PUFAs. The 26:3 acid was also found in large amounts in Baikal and some marine sponges (Latyshev et al., 1992). Low water temperatures of Lake Baikal contribute to the higher content of unsaturated and low content of saturated FAs, which facilitates support of "liquid crystal" condition of membrane structures at a certain level (Hazel, 1995; Radnaeva et al., 2017). Glyzina et al. (2017) showed that the Baikal sponge Lubomirskia baikalensis which was placed in the aquarium with a temperature increase of 10 degrees, is able to change the FA composition and restore the old FA-pool after the conditions stabilize. We can say that fatty acid 
composition is a very sensitive "natural device", fixing the presence of adaptive capabilities in the Baikal sponges. Perhaps low temperature, high pressure, high oxygen concentration and absolute darkness is responsible for the lowered content of saturated fatty acids and higher content of unsaturated acids in the studied sponges.

The analysis of lipid fraction showed that it contained from 3.3 to 8.2 rel. \% of total aldehydes. Seventeen various aldehydes were identified in $B$. intermedia profundalis. A very long-chain aldehyde 11-tetracosenal $24: 1 \mathrm{~d} 11 \mathrm{a}$ is a main aldehyde in sponges from Turka, Izhimey, Tolsty cape and Bolshie Koty. Aldehydes 16a and i17a are main in sponges from Barguzin bay and aldehydes 16a, 17a and long chain aldehydes 22:1a and 24:1a dominate in sponges from Posolsk banka. Earlier, a very long-chain aldehyde tetracosenal 17-cis-24:1a was identified and isolated in the total lipids of the endemic sponge $L$. baikalensis, which also is the main very long-chain aldehyde in the Baikal sponge B. bacilifera (Imbs\&Vereshchagin, 2005).

Analysis of lipid fraction of sponges shows that the highest content of sterols $(65.2 \%$ sterols) is in sponges from Tolsty Cape and the fewer $(38.1 \%$ sterols) in sponges from the Posolsk Banka. Sponges that inhabit the other studied locations of the lake Baikal contain from 41.3 to $56.1 \%$ sterols. The main sterol component is b-sitosterol (11.2-24.6 rel. \% of total sterols). Cholesterol is also one of the dominant sterol in sponges from Tolsty cape and consist $22.6 \%$ of total sterols.

Thus, we study lipid components of deepwater sponges $B$. intermedia profundalis for the first time. It was found that unsaturated fatty acids predominate in the fatty acid composition of the sponges. In addition, significant amounts of acids of microbial origin were detected.

\section{Acknowledgments}

Research was carried out during within the framework of the State assignment of Baikal Institute of Nature Management of SB RAS and with partial financial support from the Ministry of Science and Higher Education of Russian Federation (project №2020-1902-01-071). Thanks to senior researcher of the Limnological Institute of the Siberian Branch of the
Russian Academy of Sciences Nataly A. Bukshuk for determination of sponge species.

\section{References}

Carballeira N.M., Betancourt J.E., Orellano E.A. et al. 2002. Total synthesis and biological evaluation of (5Z, 9Z)-5,9-hexadecadienoic acid, an inhibitor of human topoisomerase. Journal of Natural Products 65(11): 17151718. DOI: $10.1021 / \mathrm{np} 0202576$

Dembitsky V.M., Rezanka T., Srebnik M. 2003. Lipid compounds of freshwater sponges: family Spongillidae class Demospongiae. Chemistry and Physics of Lipids 123: 117-155. DOI: 10.1016/S0009-3084(03)00020-3

Glyzina O.Yu., Bazarsaduyeva S.V., Glyzin A.V. et al. 2017. Modification of lipid composition in sponge Lubomirskia baikalensis under elevation of temperature in experiment. Hydrobiological Journal 53(1): 69-77. DOI: 10.1615/ HydrobJ.v53.i1.70

Hazel J.R. 1995. Thermal adaptation in biological membranes: is homeoviscous adaptation the explanation? Annual Review of Physiology 57: 19-42. DOI: 10.1146/ annurev.ph.57.030195.000315

Ichiba T., Scheuer P.J., Kellyborges M. 1995. Two cytotoxic 3,6-epidioxy fatty acids from an Indonesian sponge, Plakotris sp. Tetrahedron 51(45): 12195-12202. DOI: 10.1016/0040-4020(95)00793-8

Imbs A.B., Vereshchagin A.L. 2005. Extraction and characterization of super long-chain unsaturated aldehydes from freshwater sponge Lubomirskia baikalensis. Russian Journal of Bioorganic Chemistry 31(6): 588-592. DOI: 10.1007/s11171-005-0081-x

Latyshev N.A., Zhukova N.V., Efremova S.M. et al. 1992. Effect of habitat on participation of symbionts in formation of the fatty acid pool of fresh-water sponges of Lake Baikal. Comparative Biochemistry and Physiology 102: 961-965. DOI: 10.1016/0305-0491(92)90109-5

Radnaeva L.D., Bazarsadueva S.V., Taraskin V.V. et al. 2020. First data on lipids and microorganisms of deepwater endemic sponge Baikalospongia intermedia and sediments from hydrothermal discharge area of the Frolikha Bay (North Baikal, Siberia). Journal of Great Lakes Research 46(1): 67-74. DOI: 10.1016/j.jglr.2019.09.021

Radnaeva L.D., Popov D.V., Grahl-Nielsen O. et al. 2017. Fatty acid composition in the white muscle of Cottoidei fishes of Lake Baikal reflects their habitat depth. Environmental Biology of Fishes 100: 1623-1641. DOI: 10.1007/ s10641-017-0670-6

Zhukova N.V. 2009. Fatty acids of marine organisms: taxonomic and trophic markers. Dr. Sc. Dissertation, Pacific Institute of Bioorganic Chemistry FEB RAS, Vladivostok, Russia. (in Russian) 